Caligrama, Belo Horizonte, v. 24, n. 3, p. 47-66, 2019

\title{
As fronteiras categoriais entre preposições e advérbios nas Institutiones grammaticae de Prisciano (séc. VI): convergências entre o discurso gramatical latino e a Linguística Funcional Centrada no Uso
}

\section{The Category Boundaries between Prepositions and Adverbs in Priscian's Institutiones Grammaticae (6 ${ }^{\text {th }}$ Century AD): \\ Convergences between Latin Grammatical Speech and Usage-Based Linguistics}

Fábio da Silva Fortes

Universidade Federal de Juiz de Fora (UFJF), Juiz de Fora, Minas Gerais / Brasil fabiosfortes@yahoo.com.br

Marcela Zambolim Moura

Instituto Federal de Educação, Ciência e Tecnologia do Sudeste de Minas Gerais (IFSUDESTEMG), Rio Pomba, Minas Gerais / Brasil

marcela.moura@ifsudestemg.edu.br

Resumo: Tomando por base a discussão sobre a indefinição de fronteiras categoriais entre as preposições latinas e os advérbios, apresentada no Livro XIV das Institutiones grammaticae, de Prisciano (séc. VI d.C.), destacamos dessa reflexão algumas considerações sobre o uso linguístico apresentadas pelo gramático latino, que nos permitem associar a reflexão gramatical antiga a algumas noções linguísticas contemporaneamente desenvolvidas pela Linguística Funcional Centrada no Uso (LFCU). Buscando apontar as convergências entre a antiga descrição gramatical e postulados da Linguística Moderna, o presente artigo pretende mostrar a relevância do pensamento antigo sobre a linguagem para a pesquisa linguística contemporânea. Palavras-chave: uso linguístico; gramática latina; fronteiras categoriais. 


\begin{abstract}
Based on the discussion of the undefinition of category boundaries between the Latin prepositions and the adverbs, presented in Book XIV of Priscian's Institutiones Grammaticae (6th century AD), we highlight some considerations on the linguistic use presented by the Latin grammarian, which allow us to associate the old grammatical reflection to some linguistic notions contemporaneously developed by Usage-based Linguistics. Aiming at pointing out the convergences between the old grammatical description and principles of Modern Linguistics, this article also intends to show the relevance of the old thought on language for current linguistic research.
\end{abstract}

Keywords: use of language; Latin grammar; category boundaries.

\title{
1 Introdução
}

Das primeiras edições dos textos gramaticais antigos, datadas do século XIX, aos dias atuais, as obras dos gramáticos latinos têm sido estudadas sobretudo como um arquivo de evidências lexicais para a elaboração de dicionários modernos de latim, ou um antiquário de versos e fragmentos de autores desaparecidos na tradição manuscrita, permitindo a reconstituição de fontes e textos. Se, por um lado, essas duas dimensões do discurso gramatical antigo acentuam o interesse lexicográfico e filológico por esses textos, há relativamente poucos e recentes estudos desse corpus que destaquem seus aspectos conceituais, seu ideário linguístico e suas efetivas contribuições, a partir da Antiguidade, para a compreensão dos fenômenos linguísticos (DESBORDES, 2007; FORTES et al., 2016).

Entre mais de uma dezena de autores latinos que produziram tratados gramaticais na Antiguidade Latina, destacam-se as Institutiones grammaticae, de Prisciano, ${ }^{1}$ um monumental tratado gramatical dividido em dezoito livros, dos quais os dezesseis primeiros promovem a definição,

\footnotetext{
${ }^{1}$ As principais obras de Prisciano são, segundo uma cronologia mais aceita pelos filólogos (PASSALACQUA, 2006, p. 107): De figuris numerorum (Sobre a representação figurada dos números), De metris fabularum Terentii (Sobre a métrica das peças de Terêncio), Praeexercitamina (Exercícios preliminares), as Institutiones grammaticae (em dezoito livros) e dois pequenos tratados pedagógicos: Institutio de nomine et pronomine et uerbo (Princípios sobre o nome, o pronome e o verbo) e as Partitiones duodecim uersuum Aeneidos principalium (Análise métrica dos primeiros versos de cada canto da Eneida).
} 
a análise e a discussão acerca das partes orationis e os dois últimos se debruçam especificamente sobre a construção (ou sintaxe) da língua latina, em grande medida comparada com o grego (FORTES, 2014). A obra de Prisciano não somente é relevante por ter se colocado, na Antiguidade Tardia, como transmissora e porta-voz do pensamento grecoromano sobre a linguagem, mas também por ser aquela que representa, de certo modo, uma "refundação da gramática", ao mesmo tempo elo entre os mundos grego e latino e entre a tradição gramatical greco-romana e a gramática vernacular moderna (BARATIN; COLOMBAT; HOLTZ, 2009), oferecendo, ainda que tal não fosse seu objetivo primário, uma descrição de certo estado da língua imprescindível para o estudioso moderno e que pode trazer luz sobre variados fenômenos linguísticos do latim e das línguas neolatinas.

Neste artigo, temos como meta examinar uma questão presente no Livro XIV das Institutiones grammaticae. Nele, Prisciano dedica-se ao exame e descrição da categoria gramatical das preposições latinas (praepositiones) e, em sua parte final, reflete sobre a indefinição das fronteiras categoriais existentes entre as preposições latinas e outras categorias, especialmente o advérbio, apresentando uma discussão que faz emergirem considerações relativas ao uso linguístico e ao funcionamento das classes de palavras. Para a compreensão da discussão apresentada pelo gramático latino, propomos uma tentativa de aproximação dos aspectos linguísticos descritos naquela obra, a contribuições recentes da Linguística Funcional Centrada no Uso (LFCU), mostrando, com isso, como aquelas reflexões da antiga gramática latina ainda podem aportar elementos para compreensão dos fenômenos da linguagem em nossos dias. Para o estudo do texto de Prisciano, utilizamos a edição crítica de Baratin et al. (PRISCIEN, 2013), apresentando traduções nossas. É imperativo reconhecer que dispomos de dados oriundos das descrições gramaticais de Prisciano que, em alguns casos, são usos efetivos da língua escrita retirados da literatura latina, o que respalda a interface entre uso e estrutura, objeto de trabalho da LFCU (CEZÁRIO; FURTADO DA CUNHA, 2013, p. 18).

$\mathrm{Na}$ primeira seção, apresentamos uma descrição da discussão gramatical de Prisciano; na sequência, uma apresentação preliminar dos aspectos teóricos da LFCU mobilizados em nossa leitura e, no item final, uma reflexão analítica que pretende mostrar as convergências entre o antigo pensamento gramatical e as contribuições da Linguística Moderna. 


\section{Preposições ou advérbios? O problema dos casos ambíguos nas Institutiones grammaticae}

Produzido na parte helenófona do Império Romano, em Constantinopla, entre os fins do século V e inícios do século VI d.C., as Institutiones grammaticae certamente destinavam-se a um público que, em sua maioria, não conhecia o latim como língua materna, mas era usuário do grego como a língua franca mais falada e hegemônica na região, e que, provavelmente, tinha algum interesse em se aperfeiçoar no domínio do latim, idioma que ainda gozava de algum prestígio simbólico, empregado no direito e no âmbito das instituições romanas (ROBINS, 1993; ROCHETTE, 2007; FORTES, 2014). Tal condição de produção da obra explica o caráter particularmente exaustivo da descrição linguística dessa gramática, que, diferentemente de outras obras do gênero, perfaz uma discussão bastante longa e particularmente rica em exemplos, não raro comparando o grego com o latim.

Uma questão presente ao longo do Livro XIV das Institutiones grammaticae de Prisciano (séc. VI d.C.) é a análise das fronteiras categoriais entre as preposições latinas e outras categorias, em especial os advérbios (FORTES, 2008). Conforme destaca Prisciano, algumas preposições latinas (extra, infra, inter, adversum, intra, contra, ante, entre outras) apresentam comportamento funcional ambíguo, ora realizando funções prepositivas, ora especificando uma função adverbial. Prisciano (XIV, 4-5) oferece alguns exemplos:

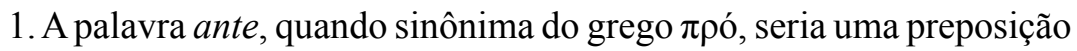
(Ante ora patrum) ${ }^{2}$ ao passo que seria um advérbio quando equivalesse a $\pi \rho{ }^{\tau} \tau \rho \rho v$ (ante leves ergo pascentur in aethere cervi); ${ }^{3}$

2. A palavra contra realizaria uma função prepositiva quando sinônima de Kató (contra contionem Metelli); $;^{4}$ podendo ainda exercer função

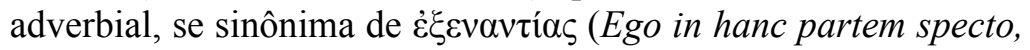
tu contra) $;{ }^{5}$

\footnotetext{
2 "diante dos pais".

${ }^{3}$ Cf. Virgílio, Écloga, I, 59: “Antes, os cervos ligeiros pastarão no céu”.

4 "Contra o tratado de Metelo".

5 "Eu observo deste lado, e tu em sentido contrário".
} 
3. A palavra adversum pode ser uma preposição, quando equivalente a غ̇ंí (Idque adversum te gratum fuisse habeo gratiam),${ }^{6}$ ou, então,

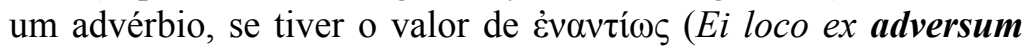
Tonstrina erat quaedam) ${ }^{7}$

4. A palavra trans, em composição, quando sinônima de $\delta i \alpha ́, \pi \alpha \rho \alpha ́$ ou vं $x \dot{\rho} \rho$ funciona como uma típica preposição latina, em vocábulos tais

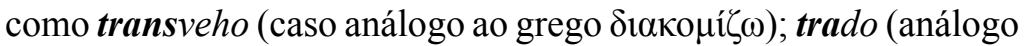
ao grego $\pi \alpha \rho \alpha \delta i \delta \omega \mu \mathrm{\imath}$ ); transgredior (análogo ao grego vi $\pi \varepsilon \rho \beta \alpha i ́ v \omega)$. Contudo, pode também realizar função adverbial equivalente a $\pi \dot{\varepsilon} \rho \alpha v$ em aposição, no sintagma trans mare $^{8}$ (equivalente ao grego $\pi \dot{\varepsilon} \rho \alpha v$ $\tau \tilde{\eta} \varsigma \theta \alpha \lambda \alpha ́ \sigma \sigma \eta \varsigma)$.

Como se destaca dos exemplos apresentados pelo gramático, a cada vocábulo latino equivaleriam duas formas gregas, conforme realizem as funções de preposição ou advérbio. A princípio, pareceria que a consideração apresentada anteriormente em sua gramática, de que o contexto teria papel primordial para a definição dos valores semânticos e gramaticais das palavras, seria o bastante para definir a contento os papéis realizados por esses termos quando a eles correspondessem diferentes funções, como nos exemplos apresentados. Entretanto, nessa parte da obra, os critérios de análise elencados por Prisciano consideram apenas acidentalmente a análise do contexto e contemplam aspectos diferenciais de outra natureza. Assim, diferenciar-se-iam preposições e advérbios, em primeiro lugar, quanto ao seu acento:

As preposições possuem acento agudo no final, tanto entre os gregos quanto entre nós, que, entretanto, é convertido em grave quando lidas com outras palavras [...]..$^{9}$ (PRISCIEN, XIV, 6)

\footnotetext{
${ }^{6} \mathrm{Cf}$. Terêncio, Andria, I, 1, 15: "E agradeço em tua presença por teres sido grato".

${ }^{7} \mathrm{Cf}$. Terêncio, Fórmio, I, 2, 38: "Naquele lugar, havia uma barbearia em frente".

${ }^{8}$ Conforme indicou o parecerista anônimo deste trabalho - ao qual agradecemos - a construção trans mare também poderia ser lida como sendo preposição (trans) + acusativo (mare). Mantivemos, contudo, a análise do gramático, que nela enxergou função adverbial.

9 "Accentum habent praepositiones acutum in fine, tam apud Graecos quam apud nos, qui tamen cum aliis legendo in gravem convertitur [...]."
} 
Sendo assim, as preposições teriam esta propriedade "fonológica" diferencial em relação aos advérbios: a de terem seus acentos agudos convertidos em graves quando lidas em conjunto com outras palavras. Casos especiais seriam os das preposições dissilábicas, quando pospostas - casos raros e poéticos -, nos quais a conversão em acento grave não seria possível. Entretanto, ainda assim, a diferenciação poderia ser feita usando-se um artifício fonológico: quando não seguidas de outras palavras, tornariam agudo o acento de sua última sílaba, em vez do antepenúltimo:

[...] como Virgílio na Eneida, I:

maria omnia circúm, ${ }^{10}$

de fato, tornamos aguda a sílaba final para que, se tornamos aguda a penúltima, a palavra não seja considerada um nome ou advérbio. ${ }^{11}$ (PRISCIEN, XIV, 6).

O segundo fator considerado na distinção entre as duas categorias é de natureza "sintática": as preposições, diferentemente dos advérbios, conectam-se a palavras casuais; precedem-nas, de fato, na maioria das vezes. Os advérbios, por outro lado, apresentam maior autonomia no interior da sentença latina, quando não se vinculam a palavras não casuais, como os verbos:

Por isso, do mesmo modo, lembro aquilo que frequentemente afirmei: todas essas preposições citadas acima, que são, sem dúvida, advérbios entre os gregos, foram classificadas entre as preposições pelos latinos, pois eram frequentemente prepostas às palavras casuais e tornavam graves os seus acentos [...]. ${ }^{12}$ (PRISCIEN, XIV, 36, grifos nossos).

\footnotetext{
${ }^{10}$ Cf. Virgílio, Eneida, I, 32: “[andavam errantes, impelidos pelos fados] ao redor de todos os mares".

11 “[...] ut Virgilius in I Aneidos:
}

maria omnia circúm;

finalem enim acuimos syllabam, ne, si paenultima acuamus, nomen vel adverbium putetur esse."

12 "Hic ergo quoque admoneo quod saepe dixi, omnia ea, quae supra dicta apud Graecos sine dubio adverbia sunt, Latinos etiam inter praepositiones ponere ea, quia frequenter casualibus praeponuntur et gravantur $[\ldots] . "$ 
Assim, o gramático também assinala importante diferença entre as palavras gregas e latinas: enquanto, como vimos anteriormente, em grego

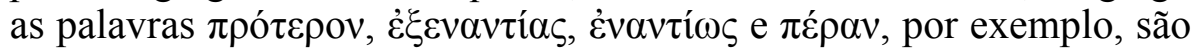
palavras perfeitamente categorizadas no âmbito dos advérbios, em latim, a respeito de ante, contra, adversum e trans, respectivamente, pareceria mais próprio dizer tratar-se de preposições em "funções adverbiais", considerando-se, sobretudo, os dois critérios assinalados acima - o seu acento e a sua sintaxe.

Um outro caso particular especialmente ambíguo apresentado por Prisciano é o das preposições supra, extra e infra. Como assinalamos acima, um dos traços distintivos das preposições em relação aos advérbios, além do seu acento, é exatamente a sua posição na sentença, como precedente (na maioria das vezes) ou subsequente (raramente, em casos poéticos) a palavras que se flexionam quanto à categoria de caso. Considerando esse fator, supra, infra e extra ficam especialmente ambíguos quando estão subentendidas ou omitidas as palavras a que esses termos se conectam, como nos exemplos abaixo (PRISCIEN, XIV, 4):

1. Ego in campo curro, tu extra.

Eu corro dentro do campo, tu [corres] fora.

\section{Ego supra aspicio, tu infra.}

Eu olho para cima, tu [olhas] para baixo.

Apesar de também possuírem funções prepositivas quando precedem palavras casuais, as palavras em negrito acima possibilitam sua leitura como advérbio, se consideramos que estão isoladas na sentença.

Esse comportamento funcional "ambíguo" - uma categoria, no caso, as preposições, com funções de outra, os advérbios - seria fenômeno também notado na própria língua grega, como salienta Prisciano (XIV, 17):

Entretanto, também fazemos isso como os autores gregos. Do mesmo modo como as preposições costumam ser empregadas no lugar dos advérbios, assim também os advérbios, no lugar das preposições. Em Homero [Il. 19, 362]:

$\gamma \varepsilon \dot{\lambda} \alpha \sigma \sigma \varepsilon \delta \dot{\varepsilon} \pi \tilde{\alpha} \sigma \alpha \pi \varepsilon \rho \grave{\chi} \chi \theta \omega ́ v$

[sobre ao céu fulgor], ri-se a terra 
$\pi \varepsilon \rho \grave{~ e m ~ v e z ~ d e ~} \pi \varepsilon ́ \rho ı \xi:$ Homero utilizou uma preposição em vez de um advérbio. $\mathrm{O}$ mesmo em:

\section{'I $\lambda$ iov $\varepsilon i \sigma \omega$}

[Para dentro de Troia]

em vez de: $\varepsilon i \varsigma$ 'I $\lambda$ ıov, ele usou o advérbio em vez da preposição. Portanto, nada espantoso encontrarem-se, também entre nós, preposições em vez de advérbios e advérbios em vez de preposições. ${ }^{13}$

Assim, estabelecendo uma relação de identidade com a língua grega, o gramático interpreta o fenômeno das preposições latinas em funções adverbiais como pertinente à própria natureza da língua, legitimada com sua ocorrência nos autores da tradição grega, entre os quais, citado textualmente, Homero. O fenômeno das preposições ante, contra, adversum e trans, entre inúmeras outras, utilizadas como

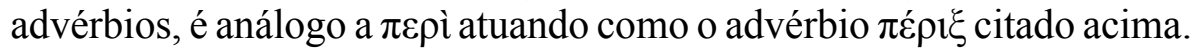

\section{A Linguística Funcional Centrada no Uso}

Modernamente, o Funcionalismo, de vertente norte-americana, se apropriou de propostas teóricas dos estudos cognitivistas - notadamente da Gramática das Construções (GOLDBERG, 1995, 2003, 2006; KAY; FILLMORE, 1999; CROFT, 2001; CROFT; CRUSE, 2004; LANGACKER, 2005; entre outros) - que permitem parcerias para o tratamento da gramática, na perspectiva da mudança (ROSÁRIO; OLIVEIRA, 2016). Nos últimos anos, as pesquisas de orientação funcionalista têm sido referenciadas sob a denominação Linguística Funcional Centrada no Uso (LFCU) - [Usage-Based Linguistics] (ALONSO; CEZÁRIO, 2015) que considera que instâncias estruturais e cognitivas e práticas sócio-comunicativas motivam a frequente

13 "Hoc tamen quoque Graecis auctoribus facimus. Sicut enim praepositiones loco adverbiorum, sic etiam adverbia loco praepositionum solent poni. Homerus:

$\gamma \varepsilon \dot{\varepsilon} \lambda \alpha \sigma \sigma \varepsilon \delta \dot{\varepsilon} \pi \tilde{\alpha} \sigma \alpha \pi \varepsilon \rho \grave{~} \chi \theta \omega ́ v$

$\pi \varepsilon \rho i ̀$ pro $\pi \varepsilon ́ \rho 1 \xi$, praepositionem posuit pro adverbio. Idem:

'I $\lambda$ lov $\varepsilon i \sigma \omega$,

pro $\varepsilon i \varsigma$ 'I $\lambda$ iov adverbium pro praepositione. Nihil igitur mirum, apud nos quoque praepositiones pro adverbiis vel adverbia pro praepositionibus inveniri." 
modulação da língua (OLIVEIRA, 2015). Nesse sentido, a LFCU não privilegia mais a forma ou o sentido do elemento linguístico em análise, nem trata de modo genérico o contexto de uso - como propôs a "versão clássica" do Funcionalismo (ROSÁRIO; OLIVEIRA, 2016, p. 235), mas confere à análise dos usos linguísticos o mesmo tratamento na dimensão da função ${ }^{14} \mathrm{e}$ na dimensão da forma e, portanto, propõe que sejam observadas com acuidade as propriedades do contexto de uso.

Nesse cenário, têm papéis importantes não só o próprio ato de fala, seus participantes - locutor e interlocutor - e o contexto discursivo, mas também as associações cognitivas que nos permitem elaborar e reelaborar os usos linguísticos. Para explicar a transformação e a organização da língua a partir da dimensão dos aspectos morfossintáticos, fonológicos, semânticos pragmáticos, discursivos e cognitivos, Traugott e Trousdale (2013) recentemente apresentaram uma proposta teórica que pretende dar conta tanto da mudança de natureza gramatical quanto da mudança de natureza lexical, a partir da compreensão de que a língua se organiza em pares de forma e de função em uma rede composta por níveis hierárquicos. A noção de organização em rede para a língua (re)direciona não só os conceitos relacionados à mudança dos fenômenos linguísticos em si como também o próprio conceito de língua - compreendida, nessa abordagem, como um conjunto de redes taxonômicas.

Um dos principais resultados teórico-metodológicos da união das perspectivas de análise da Linguística Funcional e da Linguística Cognitiva são propostas de investigação dos fatos linguísticos através da postulação da construção como unidade básica da língua. Com esse viés teórico, Traugott e Trousdale (2013) tratam sistematicamente de processos de mudança linguística através da abordagem construcional, que apresenta como princípios gerais: (a) a unidade básica da gramática é a construção, a qual consiste em um pareamento convencional entre forma e função; (b) as estruturas semântica e sintática estão diretamente relacionadas; (c) a língua apresenta uma estrutura hierárquica com ligações entre seus níveis; (d) a variação translinguística pode ser explicada de várias formas, incluindo processos cognitivos de domínios gerais e construções com variação específica; (e) a estrutura da língua é constituída/determinada pelo uso da língua. Além disso, consideram

\footnotetext{
${ }^{14}$ Adotamos o termo "função" conforme Goldberg e Micahelis (2016) e Furtado da Cunha et al. (2016).
} 
a gramática como uma "estrutura "holística", o que significa dizer que nenhum nível da gramática é central ou autônomo, de modo que a semântica, a morfossintaxe, a fonologia e a pragmática atuam juntamente na construção (TRAUGOTT; TROUSDALE, 2013, p. 3).

O modelo de construção, proposto por Traugott e Trousdale (2013), apresenta o pareamento entre forma - composta por sintaxe, morfologia e fonologia - e função-compreendida por discurso, semântica e pragmática - como uma unidade simbólica convencionalizada. $\mathrm{Na}$ perspectiva da LFCU, dentre as propostas de análise da instanciação de um novo par forma-função, considera-se o Princípio da Não Sinonímia, postulado por Goldberg (1995) - e discutido em Furtado da Cunha et al. (2016) -, de acordo com o qual duas formas diferentes não podem expressar a mesma função, embora duas funções diferentes possam ser expressas pela mesma forma.

Além disso, Traugott $(1995,2010)$ também endossa nossa discussão ao adotar a (inter)subjetivização como processo que decorre da necessidade expressiva do falante. Nesses termos, (i) a subjetivização é entendida como a inserção do falante no discurso, a partir da expressão da sua perspectiva ou da sua opinião, identificada gramaticalmente por expressões ou itens linguísticos específicos; e (ii) a intersubjetivização compreende a atenção do locutor em relação ao interlocutor - uma vez que o interlocutor é tomado como sujeito ativo na interação - e que também é gramaticalmente sinalizada (TRAUGOTT, 1995, 2010).

\section{Convergências teóricas entre a descrição gramatical antiga e as contribuições da LFCU}

A partir da abordagem construcional, todas as instâncias que representam uma construção são importantes para a criação de um novo nó na rede e para a natureza da mudança. Prisciano levanta uma questão ao longo do Livro XIV das Institutiones grammaticae (séc. VI d.C.): trata-se da análise das fronteiras categoriais entre as preposições latinas e outras categorias, em especial os advérbios (adverbia). Conforme destaca o gramático, algumas preposições latinas (extra, infra, inter, adversum, intra, contra, ante, entre outras) apresentam comportamento funcional ambíguo, ora realizando funções prepositivas, ora especificando uma função adverbial. 
Das discussões levantadas pelo gramático quanto ao comportamento ambíguo das preposições latinas, resulta a constatação de que existiria uma fronteira diluída entre os estatutos funcionais/gramaticais das categorias analisadas. Em outras palavras, a discussão apresentada pelo autor revela indícios de que não se trata de categorias absolutas, com propriedades estáveis e imutáveis na mecânica da língua; ao contrário, cada exemplo, contraste e contraexemplo discutidos parecem descrever categorias com propriedades mais ou menos homogêneas e sem fronteiras bem demarcadas entre umas e outras. Tais descrições linguísticas levamnos a pensar que a ambiguidade registrada seja indício de uma mudança linguística. Nesse sentido, a reflexão de Prisciano seria exemplar de fenômenos atualmente descritos em trabalhos como o de Ilari et al. (2008).

Assim, buscando assinalar as interfaces entre as modernas reflexões sobre a linguagem e a análise linguística apresentada por Prisciano, adotamos como referência a compreensão de que os usos, através dos quais o falante se expressa, são constituídos pelo pareamento forma-função (TRAUGOTT; TROUSDALE, 2013). Buscamos bases também no Princípio da Não Sinonímia (GOLDBERG, 1995) e no processo de (inter)subjetivização (TRAUGOTT, 1995, 2010) a fim de explicar os dados destacados pelo gramático.

Pretendemos, nesse sentido, traçar uma discussão sobre a expansão de uso de algumas preposições latinas para advérbios, que corresponde a uma mudança na língua latina e que teria sido, de certo modo, percebida pelo gramático. Com efeito, as construções destacadas pelo gramático apresentam, ao mesmo tempo, similaridades sintático-semânticas e fonológicas e diferenças pontuais que permitem a instanciação de diferentes pareamentos forma-função em um nível hierarquicamente mais particular.

\subsection{Relação forma-função dos vocábulos latinos ante, contra, adversum, trans}

Prisciano descreve três particularidades sintáticas e fonológicas que identificam usos com sentidos individuais, conforme esquematizado nos QUADROS 1 e 2, a seguir: 
QUADRO 1 - Vocábulos latinos e aspectos formais

\begin{tabular}{|l|l|l|c|}
\hline $\begin{array}{c}\text { Vocábulos } \\
\text { latinos }\end{array}$ & \multicolumn{1}{|c|}{ Aspecto fonológico } & \multicolumn{1}{|c|}{ Aspecto sintático } & $\begin{array}{c}\text { Categoria } \\
\text { morfológica }\end{array}$ \\
\hline \multirow{4}{*}{$\begin{array}{l}\text { ante } \\
\text { contra } \\
\text { adversum } \\
\text { trans }\end{array}$} & $\begin{array}{l}\text { Acento agudo convertido } \\
\text { em grave. }\end{array}$ & $\begin{array}{l}\text { Vinculam-se a palavras casuais } \\
\text { no contexto, precedendo-as ou } \\
\text { subsequentes a elas - em casos } \\
\text { raros poéticos. }\end{array}$ & Preposição \\
\cline { 2 - 3 } & $\begin{array}{l}\text { Acento agudo realocado } \\
\text { na última sílaba. }\end{array}$ & $\begin{array}{l}\text { Não se vinculam a palavras } \\
\text { casuais no contexto. }\end{array}$ & \multirow{2}{*}{ Advérbio } \\
\cline { 2 - 4 } & $\begin{array}{l}\text { Acento agudo colocado } \\
\text { na antepenúltima sílaba. }\end{array}$ & $\begin{array}{l}\text { Não se vinculam a palavras } \\
\text { casuais no contexto. }\end{array}$ \\
\hline
\end{tabular}

QUADRO 2 - Vocábulos latinos e aspectos funcionais

\begin{tabular}{|c|c|c|}
\hline $\begin{array}{l}\text { Vocábulos } \\
\text { latinos }\end{array}$ & Equivalem a preposições & Equivalem a advérbios \\
\hline ante & Sinônimo do vocábulo grego $\pi \rho o ́$ & 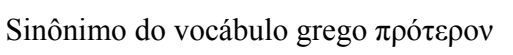 \\
\hline contra & 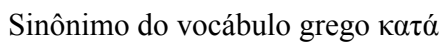 & 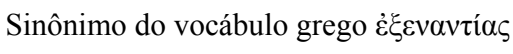 \\
\hline adversum & Sinônimo do vocábulo grego غ̇ंí & 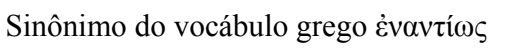 \\
\hline trans & 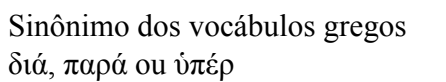 & Sinônimo do vocábulo grego $\pi \varepsilon ́ p \alpha v$ \\
\hline
\end{tabular}

Relacionando as informações dos QUADROS 1 e 2, observamos que, conforme o sentido expresso, os vocábulos latinos assumem características formais específicas. Isso significa que ante, contra, adversum e trans ilustram a possibilidade de o falante categorizar a forma linguística de acordo com a função exercida no contexto, devido a pressões semântico-pragmáticas oriundas dos padrões presentes na gramática naquele momento (FISCHER, 2011).

$\mathrm{O}$ vocábulo ante, por exemplo, ao ser usado como sinônimo do vocábulo grego $\pi \rho$ ó, vincula-se a palavras casuais no contexto, precedendo-as (ou subsequente a elas - em casos raros poéticos), e apresenta acento grave. Por apresentar-se como uma forma mais fixa na sentença, característica mais comum das preposições, o vocábulo 
ante tem, nesse pareamento forma-função, a classificação tradicional de preposição, como indica Prisciano. Já ao ser usado como sinônimo do vocábulo grego $\pi \rho$ ó $\varepsilon \rho o v$, não se vincula a palavras casuais no contexto e o acento agudo é colocado na antepenúltima sílaba. Desse modo, apresenta-se como um elemento linguístico mais solto na sentença, o que motiva o gramático a analisar esse uso e identificá-lo como advérbio.

Semelhantemente, o vocábulo adversum, ao ser usado como sinônimo do vocábulo grego éđí, vincula-se a palavras causais, precedendo-as, na maioria das vezes. Nesse caso, apresenta-se como forma fixa, característica que corrobora para a classificação como preposição, segundo Prisciano. Além disso, apresenta acento agudo convertido em grave. Como sinônimo de Ẻvavtí $\omega \varsigma$, o vocábulo adversum realiza-se de modo autônomo na sentença, pois não se agrega a outras palavras, além de apresentar acento agudo realocado na antepenúltima sílaba.

Essas especificidades formais e funcionais estão em acordo com a noção de construção em um nível menos esquemático, proposto por Traugott e Trousdale (2013). Segundo os autores, as construções apresentam graus de esquematicidade. A esquematicidade de uma construção linguística está relacionada com a extensão na qual recruta padrões mais gerais através de uma série de construções mais específicas. Os usos identificados e descritos por Prisciano seriam, portanto, construções mais específicas (TRAUGOTT; TROUSDALE, 2013, p. 16). Os padrões mais gerais são abstratos, generalizados e universais. Em um nível menos geral, encontram-se construções com comportamento sintático-semântico similar, como as construções observadas por Prisciano.

Apesar de os autores apresentarem uma proposta sólida de níveis esquemáticos e redes taxonômicas para a organização e mudança da língua, não conseguimos acessar a abstração e a particularidade de cada dado, por isso não é nosso objetivo identificar tais níveis e, portanto, a possível rede taxonômica. Como não dispomos de dados suficientes para uma análise mais ampla dos usos desses vocábulos, ressaltamos que nosso objetivo é examinar a análise apresentada por Prisciano em seu tratado e compreendê-la à luz de abordagem construcional. Dessa forma, destacamos que as observações levantadas por Prisciano vão ao encontro dessa abordagem na medida em que o autor observa funções diferentes para formas diferentes. 
Os diferentes sentidos em grego apontam que, a partir do Princípio da Não Sinonímia (GOLDBERG, 1995), há uma semântica particular para cada uso linguístico em latim. Além disso, tais usos apresentam especificidades sintáticas e fonológicas, que promovem a categorização em preposição ou advérbio por Prisciano. Nesse sentido, em um nível basilar - do que poderia ser uma rede esquemática - é possível identificar o par forma-função dos vocábulos latinos ante, contra, adversum e trans.

Em relação a esse grupo de preposições, parece que estamos diante de uma semântica de oposição. Furtado da Cunha et al. (2016, p. 59) explicam que, em termos sincrônicos, "variadas construções guardam entre si alguma relação, seja formal ou funcional", o que justifica observar o estatuto da construção a partir da análise desses dados. Tais usos apresentam-se como uma unidade convencionalizada de par formafunção. Ainda que não seja possível descrever os níveis linguísticos, é possível relacionar características da forma e da função, que o próprio gramático descreveu. Sua análise comprova que há semântica diferente para usos sintático-fonológicos diferentes.

\subsection{Relação forma-função dos vocábulos latinos supra, extra e infra}

Em relação às preposições latinas supra, extra e infra, embora o autor não aponte uma semântica específica para o uso preposicional e adverbial desses vocábulos, na perspectiva da LFCU haveria uma distinção semântico-pragmática e discursiva, pois o fato de estar subentendido um termo da sentença - como descrito por Prisciano indica um uso intersubjetivo, uma vez que o locutor considera que o interlocutor depreenderá sentido daquilo que ele não disse. Conforme propõe Traugott $(1995,2010)$, o interlocutor tem um papel ativo na elaboração do locutor, e há nisso uma intenção pragmática. Trata-se, possivelmente, de uma expansão intersubjetiva que está relacionada a uma expansão semântico-pragmática e discursiva.

Desse modo, os vocábulos supra, extra e infra foram classificados formalmente como preposições por Prisciano, ao comportarem-se como formas mais fixas, precedendo palavras casuais na sentença. Ao apresentarem-se isolados na sentença, a partir da omissão do termo que acompanham, o gramático destaca o uso ambíguo dos termos em latim, considerando-os usos adverbiais. Tais características estão sistematizadas no QUADRO 3 a seguir: 
QUADRO 3 - Vocábulos latinos e aspectos formais e funcionais

\begin{tabular}{|l|l|l|c|}
\hline $\begin{array}{l}\text { Vocábulos } \\
\text { latinos }\end{array}$ & \multicolumn{1}{|c|}{ Aspecto sintático } & \multicolumn{1}{c|}{$\begin{array}{c}\text { Aspecto semântico- } \\
\text { pragmático e discursivo }\end{array}$} & $\begin{array}{c}\text { Categoria } \\
\text { morfológica }\end{array}$ \\
\hline $\begin{array}{l}\text { supra } \\
\text { extra } \\
\text { infra }\end{array}$ & $\begin{array}{l}\text { Vinculam-se a palavras casuais } \\
\text { na sentença, precedendo-as. }\end{array}$ & Uso subjetivo & Preposição \\
\hline $\begin{array}{l}\text { supra } \\
\text { extra } \\
\text { infra }\end{array}$ & $\begin{array}{l}\text { Não se vinculam a palavras } \\
\text { casuais na sentença; são } \\
\text { isolados na sentença. }\end{array}$ & $\begin{array}{l}\text { Uso intersubjetivo- expansão } \\
\text { semântico-pragmática e } \\
\text { discursiva }\end{array}$ & Advérbio \\
\hline
\end{tabular}

Observamos no QUADRO 3 uma proposta de pareamento formafunção para os vocábulos latinos supra, extra e infra. Por meio de um fortalecimento pragmático, decorrente de crescente aumento de (inter) subjetivização (TRAUGOTT, 1995, 2010), tais vocábulos podem ser instanciados como elementos isolados na sentença. É possível observar que se encontram, nesse cenário de mudança, vocábulos latinos cujo sentido identifica posição: supra indica posição acima; extra indica posição exterior; infra indica posição abaixo ou inferior (HOUAISS, 2011).

Assim, os usos subjetivos seriam instanciados através do posicionamento do falante, gramaticalmente formalizado por expressões ou itens linguísticos que marcam suas reações em relação ao enunciado (DIAS, 2013, p. 132). Nesse sentido, as preposições latinas seriam acompanhadas por palavras identificadas no contexto da enunciação, como ocorre nesta parte da sentença: "Ego in campo curro".

Já os usos vinculados ao padrão construcional que estariam relacionados à intersubjetividade do falante marcam o enunciado com a omissão de termos, através da qual o locutor sinaliza a não neutralidade de suas escolhas, isto é, não são realizadas apenas para a declaração objetiva, mas para a participação do interlocutor no enunciado (DIAS, 2013, p. 132). Assim, o locutor imprimiria ao texto e à interação sua preocupação com a face (GOFFMANN, 1980, p. 77), reconhecendo uma posição alternativa para si mesmo no evento, marcando-a no discurso (MARTIN, 2003). No tratado de Prisciano, tais usos são considerados adverbiais por se realizarem de forma mais livre na sentença, como ocorre nesta parte da sentença "tu extra", apresentada anteriormente. 


\section{Considerações finais}

Conforme vimos, os critérios de análise elencados por Prisciano consideram apenas acidentalmente a análise do contexto e contemplam aspectos diferenciais de outra natureza, a saber, o seu acento - aspecto fonológico - e a sua sintaxe - sua ordenação na frase e suas relações com outras categorias gramaticais. Embora a descrição gramatical de Prisciano volte-se, sobretudo, para questões ligadas ao ensino de latim para falantes que provavelmente a tinham como segunda língua (ROCHETTE, 2007), do que decorre, às vezes, uma apresentação esquemática e breve, a análise da ambiguidade funcional entre preposições e advérbios latinos demonstra uma mobilização de diferentes instâncias construcionais, convergindo, portanto, com a perspectiva da abordagem construcional da mudança. De fato, nessa perspectiva, todas as instâncias que caracterizam uma construção são igualmente importantes para sua definição. Além disso, de acordo com o Princípio da Não Sinonímia, a diferença na forma das preposições - seja ela fonológica e/ou sintática - implica em uma diferença no sentido - que corresponde ao aspecto semântico dos usos - ou em uma diferença pragmática, como os usos subjetivos e intersubjetivos dos itens sob análise - que levaria em conta particularidades de estrutura informacional, como tópico e foco, além de aspectos estilísticos da construção, como o registro (GOLDBERG, 1995, p. 67), aos quais não temos acesso. Nesse caso, compreendemos se tratar de uma expansão semântico-pragmática atrelada ao uso adverbial dos vocábulos latinos.

Finalmente, parece-nos ainda digno de nota que o fenômeno linguístico retratado por Prisciano parece antever a dinâmica de mudança dessas classes de palavras da língua latina para o português, conforme estudos mais recentes. Ilari et al. (2008) explicam que, ao longo dos tempos, a classe das preposições passou por fases com diferentes processos na língua latina. Segundo os autores, na fase mais antiga da língua houve um desgaste que levou ao desuso e até ao desaparecimento de muitas preposições latinas (ILARI et al., 2008, p. 790). Desse modo, a fim de suprir as necessidades expressivas ou para concretizar no uso as preposições que permaneceram, houve a combinação de duas ou mais preposições, como "de + ex + de", formando "desde"; "per + ad", formando "para"; "ad + post"; formando "após", e ainda a justaposição de elementos latinos, dando origem a advérbios, como "de + intro", formando 
"dentro"; "de + post", formando "depois"; "de + magis", formando “demais" (ILARI et al., 2008, p. 790). As combinações realizadas, nesta fase da língua latina, geraram locuções prepositivas ou adverbiais.

Em relação ao português, Oliveira e Cezário (2012) esclarecem que é comum observarmos o desenvolvimento de advérbios por fusão e coalescência - relacionados ao processo de gramaticalização envolvendo uma preposição e um sintagma nominal. Nessa trajetória, segundo os autores, os termos perdem o sentido concreto e denotam sentido interpessoal.

Para além de um registro sumário e detalhista, Prisciano sinaliza a ambiguidade do uso das preposições. Apesar de o acesso aos dados ser restrito - haja vista o fato de observarmos os dados descritos pelo gramático - é possível compreender, através das abordagens elencadas para esse diálogo, que, a depender do sentido expresso, os vocábulos latinos apresentam comportamento preposicional ou adverbial para o falante atingir seu propósito comunicativo, selecionando a forma que atende a uma função específica. Pelo viés da abordagem construcional, tais construções são associadas por semelhanças e por diferenças formais e funcionais, cujo resultado é a frequente renovação da língua.

\section{Referências}

ALONSO, K. S. B.; CEZÁRIO, M. M. A dimensão do uso na gramaticalização de construções. In: OLIVEIRA, M. R.O; ROSÁRIO, I. C. (org.). Linguística centrada no uso: teoria e método. Rio de Janeiro: Lamparina: FAPERJ, 2015.

BARATIN, M.; COLOMBAT, B; HOLTZ, L. Priscien: Transmission et refondation de la grammaire de l'Antiquité aux Modernes. Turnhout: BREPOLS, 2009. DOI: https://doi.org/10.1484/M.SAEB.6.09070802050003050300070401.

CEZÁRIO, M. M; FURTADO DA CUNHA, M. A. (org.). Linguística centrada no uso: uma homenagem a Mário Martelotta. Rio de Janeiro: Mauad X: FAPERJ, 2013.

CROFT, W. Radical Construction Grammar: Syntactic Theory in Typological Perspective. New York: Oxford University Press, 2001. DOI: https://doi.org/10.1093/acprof:oso/9780198299554.001.0001. 
CROFT, W; CRUSE, A. D. Cognitive Linguistics. Cambridge: Cambridge University Press, 2004. DOI: https://doi.org/10.1017/ CBO9780511803864.

DESBORDES, F. Idées grecques et romaines sur le langage: travaux d'histoire et d'épistémologie. Lion: ENS Editions, 2007.

DIAS. N. B. A marca da (inter)subjetividade na sentença complexa subjetiva. Confluência, Rio de Janeiro, v. 44/45, p. 83-106, 2013.

FISCHER, O. Grammaticalization as analogically driven change? In: NARROG, H.; HEINE, B. (ed.). The Oxford Handbook of Grammaticalization. New York: Oxford University Press, 2011. DOI: https://doi.org/10.1093/oxfordhb/9780199586783.013.0003.

FORTES, F. Comparações e contrastes entre o grego e o latim como estratégia explicativa no De constructione, de Prisciano (séc. VI d.C.). Classica-Revista Brasileira de Estudos Clássicos, Belo Horizonte, v. 27, n. 2, p. 31-51, 2014. Disponível em: https://classica.emnuvens. com.br/classica/article/view/221. Acesso em: jun. 2019. DOI: https:// doi.org/10.24277/classica.v27i2.221.

FORTES, F. et al. Reabilitando os pensadores antigos para uma Linguística do século XXI. Codex - Revista de Estudos Clássicos, Rio de Janeiro, v. 4, n. 2, p. 53-73, 2016. Disponível em: https://revistas.ufrj. br/index.php/CODEX/article/view/5347. Acesso em: jun. 2019. DOI: https://doi.org/10.25187/codex.v4i2.5347.

FORTES, F. Os marcadores discursivos do latim: reflexões textuais e pragmáticas sobre as conjunções, interjeições e preposições em Donato e Prisciano. 2008. 130f. Dissertação (Mestrado em Linguística - Letras Clássicas) - Instituto de Estudos da Linguagem, Universidade Estadual de Campinas, Campinas, 2008.

FURTADO DA CUNHA, M. A.; SILVA, J. R.; BISPO, E. B. O pareamento forma-função nas construções: questões teóricas e operacionais. Revista Linguística, Rio de Janeiro, v. 12, p. 55-67, dez. 2016.

GOFFMAN, E. A elaboração da face: uma análise dos elementos rituais na interação social. In: FIGUEIRA, S. A. (org.). Psicanálise e ciências sociais. Rio de Janeiro: Francisco Alves. 1980. p. 76-114. 
GOLDBERG, A. Constructions at Work: The Nature of Generalization in Language. Oxford: Oxford University Press, 2006.

GOLDBERG, A. Constructions: A New Theoretical Approach to Language. Trends in Cognitive Sciences, Cambridge (MA), v. 7, n. 5, 2003. DOI: https://doi.org/10.1016/S1364-6613(03)00080-9.

GOLDBERG, A. E. Constructions: A Construction Grammar Approach to Argument Structure. Chicago: University of Chicago Press, 1995.

GOLDBERG, A.; MICHAELIS, L. A. One Among many: Anaphoric One and Its Relationship to Numeral One. Cognitive Science, [S.l.], v. 41, n. 2, p. 233-258, 2016. DOI: https://doi.org/10.1111/cogs.12339.

HOUAISS, A. (ed.). Dicionário Houaiss Conciso. São Paulo: Moderna, 2011.

ILARI, R. et al. A preposição. In: ILARI, R.; NEVES, M. H. (org.). Gramática do português culto falado no Brasil. Campinas: Editora da Unicamp, 2008. v. 2, p. 623-802.

KAY, P.; FILLMORE, C. Grammatical Constructions and Linguistic Generalizations: The What's X Doing Y? Construction. Language, Washington (DC), v. 75, p. 1-33, mar. 1999. DOI: https://doi. org/10.2307/417472.

LANGACKER, R. W. Construction Grammars: Cognitive, Radical and Less so. In: IBÁÑEZ, R. M.; F. J.; CERVEL, M. S. P. (ed.). Cognitive Linguistics: Internal Dynamics and Interdisciplinary Interaction. Berlin: Mouton de Gruyter, 2005. (Série Cognitive Linguistics Research, 32).

MARTIN, J. R. Introduction. Text: Interdisciplinary Journal for the Study of Discourse, Berlin, v. 23, n. 2, p. 171-181, 2003. DOI: https://doi. org/10.1515/text.2003.007.

OLIVEIRA, M. R. Contexto: definição e fatores de análise. In: OLIVEIRA, M. R.; ROSÁRIO, I. C. (org.) Linguística centrada no uso: teoria e método. Rio de Janeiro: Lamparina: FAPERJ, 2015. v. 1, 160 p. OLIVEIRA, M. R; CEZÁRIO, M. M. (org.) Adverbiais: aspectos gramaticais e pressões discursivas. Niterói: Editora da UFF, 2012.

PASSALACQUA, M. Priscianus Caesarensis. In: BROWN, K. (ed.). Encyclopedia of Language and Linguistics. 2. ed. Rio de Janeiro: 
Elsevier, 2006. p. 107-108. DOI: https://doi.org/10.1016/B0-08-0448542/02827-3.

PRISCIEN. Grammaire. Livres XIV, XV, XVI - Les invariables. Texte latin, traduction introduite et annotée par le Groupe Ars Grammatica, animé par Marc Baratin et composé par Fréderique Biville et al. Paris: Vrin, 2013.

ROBINS, R. The Byzantine Grammarians: Their Place in History. Nova York: Mouton de Gruyter, 1993. DOI: https://doi. org/10.1515/9783110857221.

ROCHETTE, B. L'enseignement du latin dans la partie hellénophone de l'Empire romain: objectifs et méthodes. In: SANCHEZ-OSTIZ, A.; GUERRA, J. B. T.; MARTÍNEZ, R. De Grecia a Roma y de Roma a Grecia: un camino de ide y de vuelta. Esparza de Galar (Navarra): Ediciones Universidad de Navarra, 2007. p. 47-64.

ROSÁRIO, I. C.; OLIVEIRA, M. R. Funcionalismo e abordagem construcional da mudança. Alfa, São Paulo, v. 60, n. 2, p. 233-259, 2016. DOI: https://doi.org/10.1590/1981-5794-1608-1.

TRAUGOTT, E. C. (Inter)Subjectivity and (Inter)Subjectification: A Reassessment. In: DAVIDSE, K.; VANDELANOTTE, L.; CUYCKENS, H. (ed.). Subjectification, Intersubjectification and Grammaticalization. Berlin; New York: De Gruyter Mouton, 2010. p. 13-26.

TRAUGOTT, E. C. Subjectification in Grammaticalization. In: STEIN, D.; WRIGHT, S. (ed.). Subjectivity and Subjectification. New York: Cambridge University Press, 1995.

TRAUGOTT, E. C.; TROUSDALE, G. Construcionalization and Constructional Changes. New York: Oxford University Press, 2013. DOI: https://doi.org/10.1093/acprof:oso/9780199679898.001.0001.

Recebido em: 27 de maio de 2019. Aprovado em: 16 de julho de 2019 